\title{
ВТРАТИ СТЕГАНОГРАФІЧОЇ ІНФОРМАЦЇ̈ У ГРАФІЧНОМУ КОНТЕЙНЕРІ ФОРМАТУ JPG
}

У даній статті проаналізовані результати перевірки можливостей використання стеганографічних алгоритмів, що застосовують у якості контейнера файли зображень JPG. Досліджено ступінь втрати даних у цьому форматі растрової графіки.

Ключові слова: інформаційна безпека, стеганографія, растрова графіка,

На сьогоднішній день, в епоху цифрових технологій, найбільш вживаними є методи приховання інформації в цифрових контейнерах - файлах, якими можуть оперувати ЕОМ. Найбільшого практичного застосування набули такі, що використовують у якості контейнерів графічні та аудіо файли. Як правило ними виступають формати без втрат даних, наприклад BMP, TIF, для першого i WAV для другого випадку відповідно. Однак на сьогоднішній день такі формати використовуються дуже рідко. Це зумовлено їх відносно великим розміром, що викликає певні ускладнення при маніпуляціях 3 ними. Тому при захисті інформації застосування таких форматів може викликати підозру на наявність прихованих в них даних.

Тривалий час вважалося, що формати файлів зі стисненням непридатні для використання у якості контейнерів, адже при цьому може постраждати прихована в них інформація, тобто може виникнути іiі повна або часткова втрата. Проте аналіз літератури [24] вказує на існування таких стегоалгоритмів, які є стійкими до стиснення. В зв'язку з цим, метою даної роботи була перевірка придатності використання у якості контейнера поширеного формату JPG, а також супутнього спотворення інформації при стисненні.

При проведенні дослідження були використані напівтонові (256 градацій сірого) тестові зображення, яскравість усіх точок яких відома. Вони стандартними програмними методами перетворювались у файли графічних даних формату JPG 3 різним ступенем стиснення. Наступним кроком було вилученням бітової матриці з файлу і їі дослідження на предмет збереження структури та значень яскравості пікселів. Також за виразом (1) визначалася яскравісна сума (S) тестового зображення як чисельна характеристика ступеня спотворення.

$$
S=\sum_{i=1}^{255} i \cdot N_{i}
$$

де $\boldsymbol{N} \boldsymbol{i}$ - число пікселів, що мають однаковий яскравісний атрибут $\boldsymbol{i}$.

Тестове зображення нескладно побудувати, знаючи специфікацію графічного файлу або за допомогою програм MathCAD, MathLAB тощо, перетворити задану бітову матрицю у графічний файл.

Відповідно з цим було створено 4 бітові матриці тестових об'єкті у вигляді 8 полів різної яскравості прямокутної форми (рис. 1). Розміри кожного поля 10 на 40 пікселів. Усі поля відокремлені смугами більшої яскравості шириною в один піксел. Це дозволить більш наглядно виявити спотворення просторової структури.

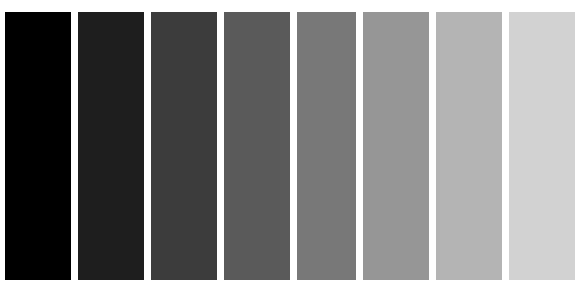

Рис. 1. Ескіз тестового зображення 
Перше тестове зображення має малу просторову глибину і складається 3 полів малої яскравості (значення яскравостей полів відповідно 0, 1, 2, 3, 4, 5, 6, 7 і відокремлюючих смуг $-8)$.

Результати дослідження розподілу яскравості полів першого тестового зображення при різних ступенях стиснення (для прикладу були взяті центральні рядки вилучених бітових матриць) подані на рис.2. Очевидно, що зображення зберігає свою просторову структуру лише при мінімальному стисненні (100\% якості; рис. 2, крива 1). При більших ступенях стиснення відбуваються значні спотворення (90\% - 40\% якості; рис. 2, крива 2), усереднення просторових даних (30\% - 10\% якості; рис. 2, крива 3) і навіть повна їх втрата (0\% якості; рис. 2, крива 4).

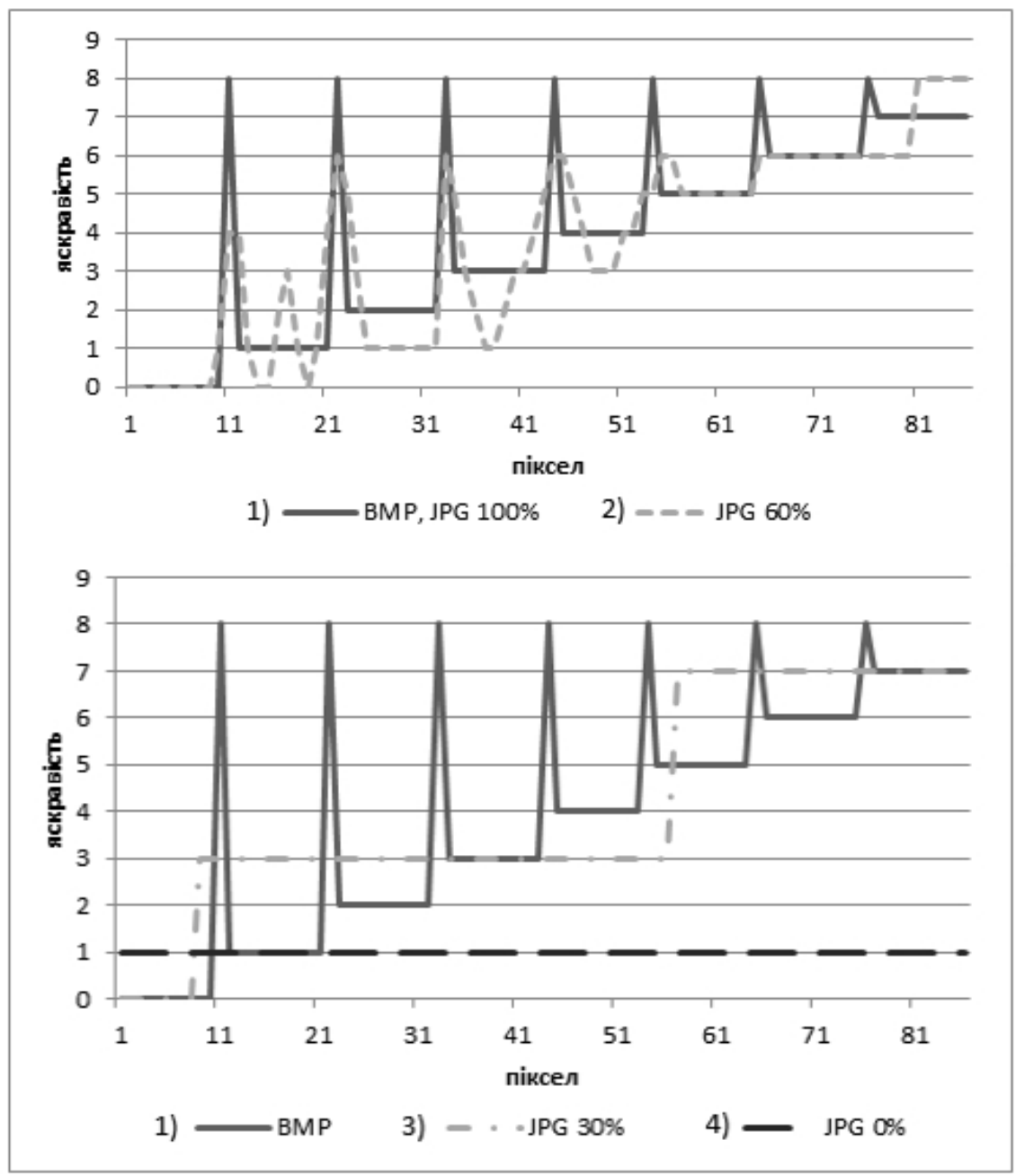

Рис. 2. Розподіл яскравості полів першого зображення при різному ступені стиснення

Результати дослідження залежності фотометричної суми від ступеня стиснення подані в табл. 1. Незважаючи на суттєву візуальну різницю між деякими стисненими зображеннями та оригіналом, розбіжність їх яскравісних сум відносно мала (в середньому 5\%). 3 одного боку це свідчить про певну неприйнятність чисельної оцінки спотворень цим методом, 3 іншого, дає змогу стверджувати про можливу доцільність використання формату JPG для фотометричних досліджень у випадках, коли можна знехтувати просторовою структурою зображення (при сталій середній яскравості на одиницю площі, суттєво зменшується розмір файлу).

Аналогічні результати були отримані при дослідженні двох наступних зображень: 3 малою просторовою глибиною та середніми (120-128) і високими (247-255) значеннями 
яскравості полів. Причому на відміну від попереднього випадку максимальна розбіжності між яскравіснимии сумами значно знизилася (від 70\% до 3\%).

Четверте штучне тестове зображення мало значно більшу (порівняно 3 попередніми) просторову глибину зі значнням яскравості полів відповідно 0, 30, 60, 90, 120, 150, 180, 210 і відокремлюючих смуг - 255.

Результати дослідження розподілу яскравості полів четвертого тестового зображення при різних ступенях стиснення подані на рис.3.

Як видно 3 рис. 3, загальна просторова картина зберігається при усіх ступенях стиснення, а найбільш істотні спотворення припадають на діапазон середніх та високих яскравостей. Максимальна розбіжність фотометричної суми зображень від еталонної знизилась до $1 \%$

Додатково було проведено дослідження по стисненню і відновленню фотометричного зображення світлового отвору сигнального прожектора (рис. 4) розміром 100 на 100 пікселів 3 подібною просторовою глибиною та однаковою кількістю градацій, що і в попередньому тестовому зображенні. Результати дослідження розподілу яскравості полів світлового отвору прожектора при різних ступенях стиснення подані на рис.5.

Аналіз отриманих даних показав, що найбільшому спотворенню підлягають лише ті ділянки стиснених зображень, які мають малу локальну просторову глибину (рис 4). Максимальна розбіжність яскравісної суми стиснених зображень світлового отвору від їх оригіналу не перевищувала $0,6 \%$. Це дозволяє стверджувати, що для більшості випадків, при будь-якому ступені стиснення, середня яскравість на одиницю площі буде мати відхилення, яким можна знехтувати.

Залежність фотометричної суми точок та розміру файлу від ступеня стиснення Таблиця 1

\begin{tabular}{|c|c|c|c|c|c|}
\hline Ступінь якості, \% & \multicolumn{3}{|c|}{ Яскравісна сума } & \multicolumn{3}{c|}{ Розмір файлу, байт } \\
\hline & JPG & $\begin{array}{c}\text { Відхилення від } \\
\text { ВМР, \% }\end{array}$ & JPG & JPG* & BMP \\
\hline 100 & 13280 & 0 & 723 & 420 & 4598 \\
\hline 90 & 13080 & $-1,5$ & 522 & 308 & - \\
\hline 80 & 13480 & 1,5 & 473 & 269 & - \\
\hline 70 & 13960 & 5,1 & 420 & 216 & - \\
\hline 60 & 12880 & -3 & 409 & 206 & - \\
\hline 50 & 12480 & -6 & 403 & 203 & - \\
\hline 40 & 14160 & 6,6 & 395 & 199 & - \\
\hline 30 & 14160 & 6,6 & 377 & 181 & - \\
\hline 20 & 13760 & 3,6 & 376 & 181 & - \\
\hline 10 & 17280 & 30 & 375 & 177 & - \\
\hline 0 & 3440 & -74 & 372 & 174 & - \\
\hline & $* 3$ оптимізацією таблиці Хафмана & & \\
\hline
\end{tabular}




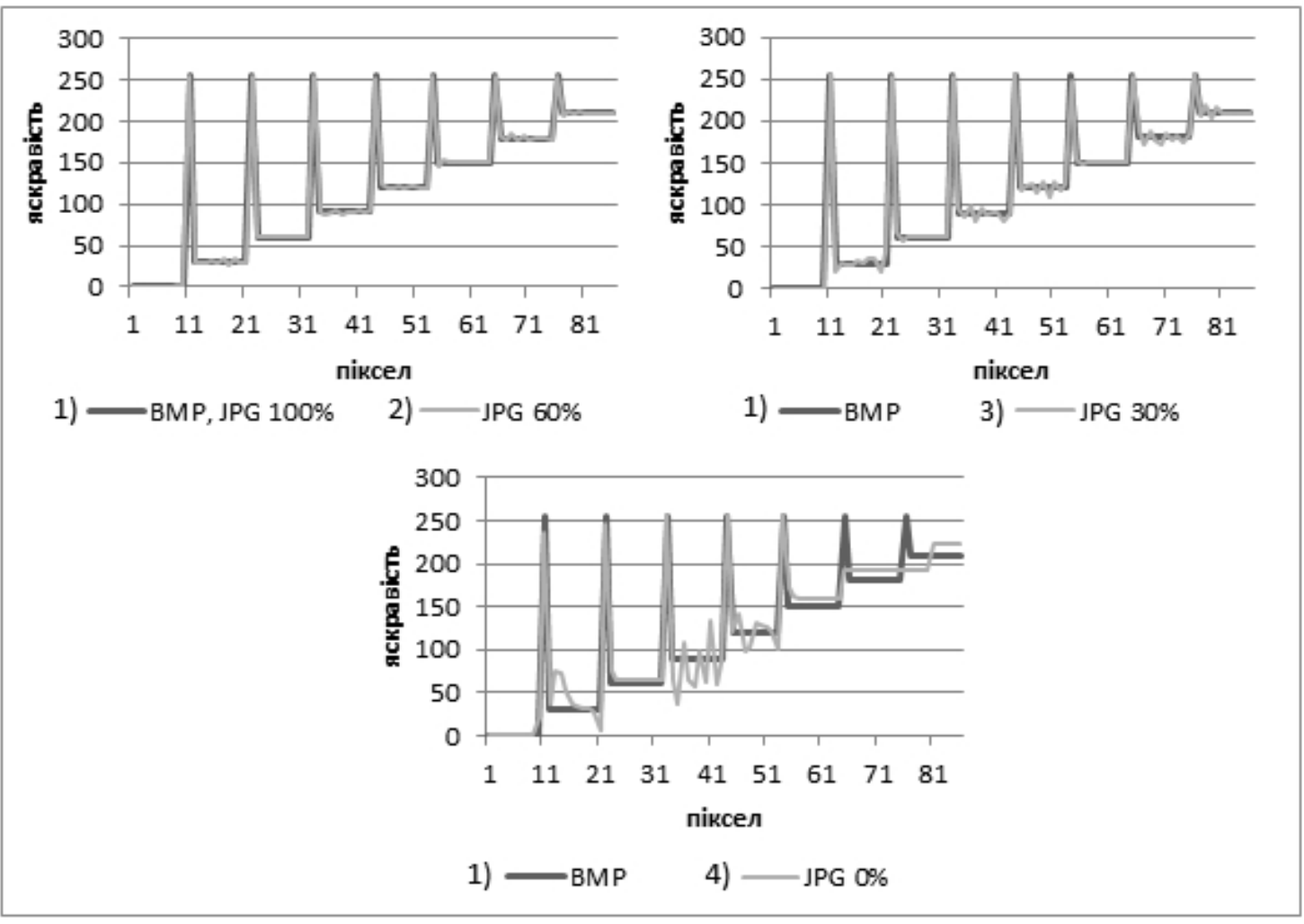

Рис. 3. Розподіл яскравості полів четвертого зображення при різних ступенях стиснення

В результаті дослідження була підтверджена придатність використання формату растрових зображень JPG у якості контейнеру для приховування інформації. Було встановлено, що використання відповідних стеганографічних алгоритмів обмежується не лише їх завадостійкістю, а в першу чергу ступенем стиснення та просторовою структурою графічного файлу.
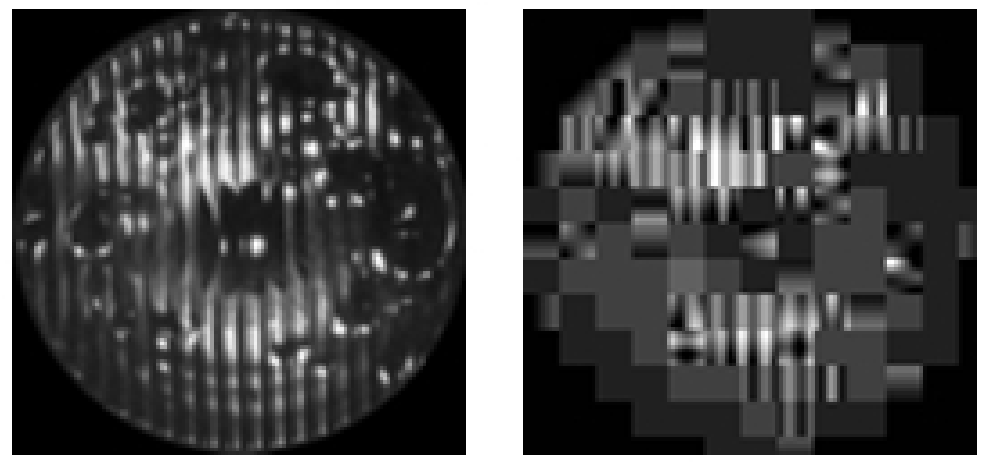

Рис. 4. Ескізи зображень світлового отвору прожектора: - оригіналу (зліва) та з максимальним стисненням (справа)

Відповідно для досягнення мінімальних спотворень прихованої інформації необхідно ретельно обирати не тільки максимально-допустимий ступінь стиснення, але й власне саме зображення. Так, наприклад, для зображень, що мають низькі просторові частоти (мало мілких деталей) та високий діапазон яскравостей, можна застосовувати більші ступені стиснення при однаковій вірогідності появи спотворення.

Визначені максимальні відхилення яскравісних сум зображень від еталонних дозволяють стверджувати про доцільність використання формату JPG (так само як i традиційних RAW, TIF, BMP) для фотометричних досліджень у випадках, коли можна знехтувати просторовою структурою зображення. При цьому допустимо використовувати більші ступені стиснення виходячи із похибки прийнятної для практичних потреб. 


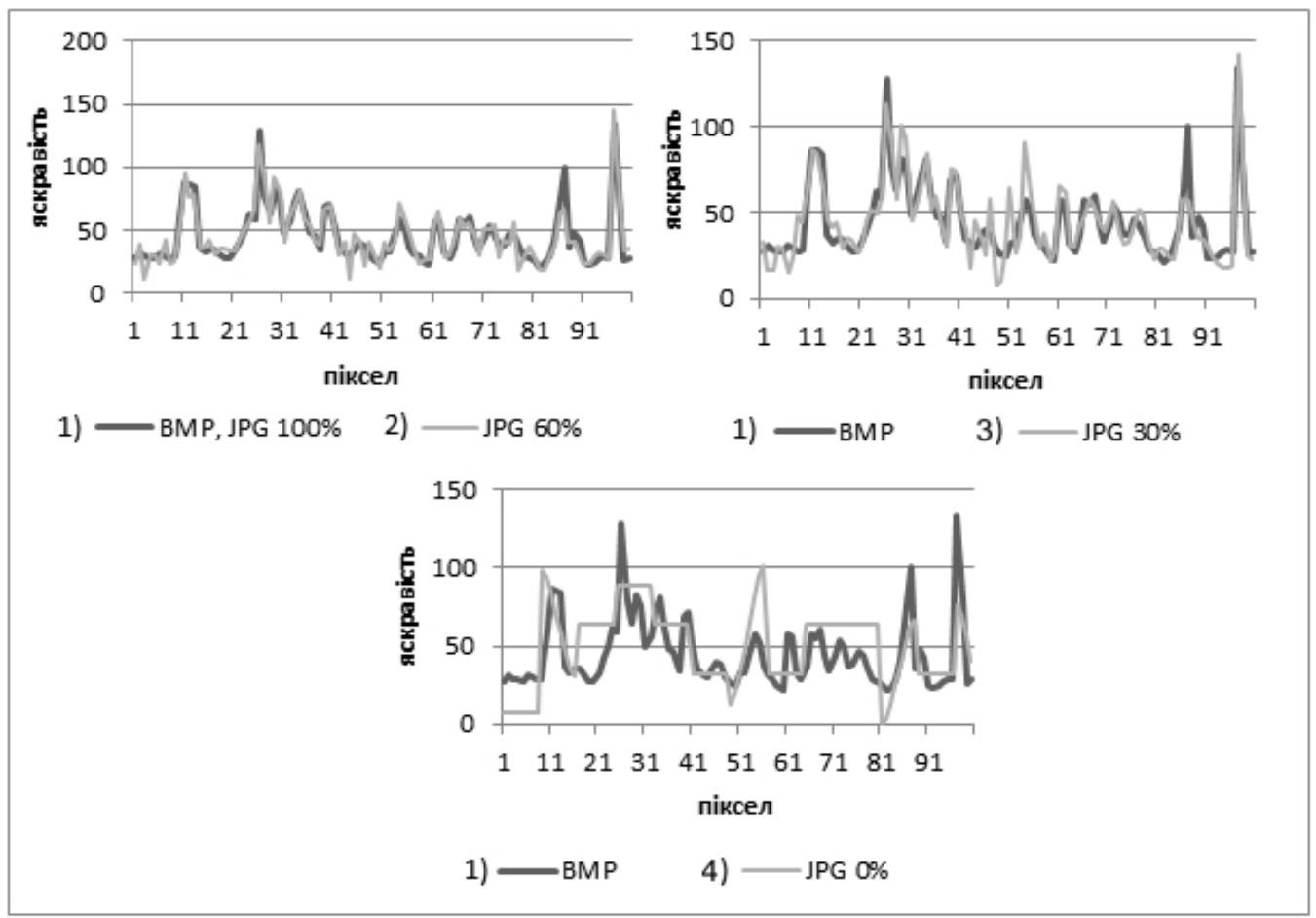

Рис. 5 Розподіл яскравості полів світлового отвору прожектора при різних ступенях стиснення

\section{ЛІТЕРАТУРА}

1. Watson A. The cortex transform: rapid computation of simulated neural images // Computer Vision, Graphics, and Image Processing. 1987. Vol. 39. № 3. P. 311-327.

2. Chae J. J. Robust Techniques for Data Hiding in Images and Video. PhD thesis, CA, USA, 1999.

3. Piva A., Barni M., Bartolini F., Cappellini V. A watermarking technique for the protection of digital images IPR // Proceedings of European Multimedia, Microprocessor System and Electronic Commerce Conference and Exhibition: Advances in Information Technologies: The Business Challenge. 1997. P. 636-643.

4. Fridrich J. Combining low-frequency and spread spectrum watermarking // Proceedings of the SPIE Symposium on Optical Science, Engineering and Instrumentation. 1998. 